\title{
How competitive forces sustain electric vehicle development
}

\author{
J.H. Wesseling *, J. Faber, M.P. Hekkert \\ Copernicus Institute of Sustainable Development, Utrecht University, Utrecht, The Netherlands
}

\section{A R T I C L E I N F O}

\section{Article history:}

Received 23 September 2012

Received in revised form 8 February 2013

Accepted 9 February 2013

Available online 9 March 2013

\section{Keywords:}

Electric vehicle

Low Emission Vehicle

Sustainable mobility

Patent

Technological competition

Rivalry

\begin{abstract}
A B S T R A C T
This patent study researches the relation between competitive forces and the continuation of waves of Low Emission Vehicle (LEV) development. The competitive forces included are rivalry, dispersion referring to competition in general, and the presence of new entrants. We identify four waves of LEV development over the period 1990-2010, two of which were broken before becoming a commercial success, one that was continued, and one that is the current wave of Battery Electric Vehicle (BEV) development. Although the presence of new entrants could not be tested for all cases, our findings suggest that the combination of rivalry and dispersion positively relates to continued LEV development. We conclude that continuation of the current wave of BEV development is likely, as it is supported by increases in rivalry, dispersion and the presence of new entrants.
\end{abstract}

(c) 2013 Elsevier Inc. All rights reserved.

\section{Introduction}

In the mobility system, emissions from internal combustion engine vehicles (ICEVs) have significant impacts on climate change and on the atmosphere, e.g. through smog formation [1]. It is therefore important that the mobility system becomes more sustainable. Within the portfolio of technologies that are developed to attain a sustainable mobility system, technologies such as the Battery Electric Vehicle (BEV), the Hydrogen Fuel Cell Vehicle (HFCV), and the Hybrid Electric Vehicle (HEV), present a good alternative to the established ICEV [2]. We classify these technologies as Low Emission Vehicles (LEVs). Each of these LEVs contains a partial or full electric drivetrain and constitutes a technology that is significantly different from the established ICEV. These solutions have gained increasing attention and are becoming ever better developed $[3,4]$.

Competence-destroying LEVs like the BEV and HFCV that render obsolete established ICEV technology [5] have enjoyed a trend of increasing attention and decades of technological development [6,7], though they have not experienced

\footnotetext{
* Corresponding author at: Heidelberglaan 2, 3584 CS Utrecht, The Netherlands. Tel.: + 31 302536748; fax: + 31302532746.

E-mail addresses: j.h.wesseling@uu.nl (J.H. Wesseling), j.faber1@uu.nl (J. Faber), m.p.hekkert@uu.nl (M.P. Hekkert).
}

commercial success. ${ }^{1}$ On the one hand, this is due to the established ICEV, which automotive firms have continuously developed to make it cheaper and more sustainable [3]. On the other hand, however, the failure of these competencedestroying LEVs can be explained by their pattern of development, which has always been characterized by hypes: periods of increased optimism succeeded by periods of disappointment. In this paper we focus on hypes to explain the presence and absence of LEVs' commercial success. We refer to the periods of increased technological development that accompany these hypes as 'waves of LEV development'. Waves of development are broken due to a successive period of disappointment [8]. A notable exception is the HEV. The technology is less competence-destroying and the wave of development is continued, leading to actual diffusion of this technology in the market and commercial success [9].

Another wave of LEV development has recently emerged. After the high hopes for hydrogen as a fuel plummeted in the last 5 years, the new hope of the automotive sector seems to be the BEV. Several car manufacturers are testing BEVs and

\footnotetext{
1 Although no recent successes have been attained, until the early 1900s more BEVs were sold than there were ICEVs [10].
} 
investment decisions have been made to build factories. But it is uncertain whether this is just another hype that will be accompanied by disillusion in the near future, or whether this wave of technological development will actually become a continued one that may lead to commercial success.

To assess the chances of success of a new technology, in most cases technological characteristics and price developments are used. In earlier hypes of LEVs we witnessed intense disagreement between technological experts on expected technological performance and price developments $[10,11]$. Therefore, in this study we take another approach. We assess how the industry structure develops around emerging LEVs. Ceteris paribus, our basic assumption is that when an increased number and higher diversity of firms move into a new trajectory leading to more technological competition, the new technology is more likely to be continuously developed, improving its chances of commercial success. This relation between competition and innovation draws on an extensive body of literature that describes a positive relation between competition and continued technological development $[12,13]$. Literature also shows that this applies to LEV development $[9,14,15]$.

These competitive forces can be broken down into different dimensions. It is important to distinguish 1) the level of rivalry between car manufacturers, 2) the level of dispersion: the extent to which different types of organizations contribute to technological development and 3) the presence of new entrants. This unprecedented set of dimensions draws from Technology Life Cycle literature [13] and builds on previous LEV studies [16].

In this article we first test whether the presumed positive correlations between these forces and continued technological development hold for three waves of technological LEV development. Subsequently, we analyze how these competitive forces relate to the fourth and current wave of BEV development to assess if continued technological development is now more likely to occur than during previous waves. Consequently, our research question is as follows: "How did the forces of rivalry, dispersion and the presence of new entrants affect the duration of earlier waves of LEV development and how do these competitive forces affect the chances of continuation of the current wave of BEV development?"

In this paper we study the relationship between competitive forces and waves of LEV development through patents. We analyze the technological fields of BEV, HEV and HFCV. In this patent study we intend to make four additions to the existing literature. Three are related to the literature on LEV forecasting and one to the general literature on technological forecasting.

- First, the timeframe of study comprises the period 1990-2010, enabling us to study the contemporary wave of BEV development that falls outside the timeframe of most previous studies $[3,7,14]$.

- Second, we relate LEV development to a set of competitive forces not studied before and in doing so we broaden the scope of research outside the frequently studied population of large car manufacturers [3,7,14].

- Third, we not only use the conventional search queries applied in previous studies, but also add search queries on the component level of an LEV to enhance the capture of relevant patents, which results in a more comprehensive study of technology development.

- Fourth, we develop a set of indicators that are useful for technological forecasting. Until now, very little attention has been given in forecasting literature to using data on technological competition in order to assess future technological developments.

The remainder of this paper is structured as follows. In Section 2 we first elaborate on the waves of LEV development in the period 1990-2010 and subsequently describe how the competitive forces positively influence continuation of waves of LEV development. In the subsequent methodology section we elaborate on the research design and methods of data collection and analysis. We present the results and analysis in Section 4. Finally, in Section 5 we provide some conclusions, a discussion and some recommendations for further research.

\section{Theoretical framework}

This study on waves of technological development lies embedded within the larger body of literature that focuses on technological change. Perhaps the most well-known theoretical model is the Product Life Cycle (PLC), which is intertwined with industry and technology life cycles $[5,17,18]$. The PLC describes a cyclical process of transition where a radical innovation introduces an era of ferment, which is ended by the emergence of a dominant design that initiates an era of incremental innovation, which in turn is ended by the next radical innovation $[5,17,18]$. In the automotive industry, research shows that the LEVs under study are still in the era of ferment $[9,19]$, whereas the ICEV has been the mature technology that was improved by incremental innovation for decades. Our study on waves of LEV development lies embedded within the PLC's era of ferment, which so far left these development dynamics largely unaccounted for. The PLC stresses that competitive forces play an important role in facilitating the development of emerging technologies like LEVs, especially in their era of ferment $[5,17,18]$. Consequently, in this theory section we discuss the relation between waves of technological development and a set of competitive forces to make predictions about the continuation of these waves of development.

\subsection{Waves of development}

The period 1990-2010 experienced four waves of LEV development. The first wave concerns the broken wave of BEV development in the early nineties [20,21] and was initiated by the demonstration of GM's working BEV prototype, the EV1. ${ }^{2}$ Other large car manufacturers quickly followed GM with increased investments in BEV development and assembled their own working BEV prototypes [20,21]. However, this period was followed by a period of disappointment. High costs and low range were reported as technological showstoppers. The second broken wave comprised the development of HFCVs from the late 1990s to the mid 2000s [14,22]. This wave was

\footnotetext{
2 The demonstration of this working prototype is argued to have triggered the Zero Emission Vehicle mandate by the Californian Air Resources Board as an important stimulus for LEV development [43].
} 
initiated by Daimler moving first into HFCV development, and other car manufacturers followed quickly [14,22]. Reasons for the crumbling belief in this option were high costs for fuel cells and infrastructure problems. Third was the continued wave of HEV development that led to commercial success and which started in the late nineties. This wave was pioneered by Toyota and Honda, who brought HEVs to market in 1997 and 1998 respectively [23]. Triggered by high sales, various other car manufacturers invested in HEV development and marketed their own vehicles starting in 2006, which further increased commercial success $[15,24]$. A fourth wave concerns the BEV development that started in approximately 2006 [19]. This wave was different from previously discussed waves in the sense that new entrants reportedly played an important role in triggering it: numerous new entrants began producing BEVs from 2006 onwards, whereas most incumbent car manufacturers did not introduce their own prototype or production vehicles until 2009 [19]. Since the automotive sector actively uses patents to protect intellectual property, the previously discussed four waves of LEV development should be reflected in patent data. Hence the following proposition:

Proposition 1. Waves of LEV development identified in previous studies are characterized by technological progress and therefore reflected by peaks in patent data.

\subsection{Competitive forces that influence continuation of waves of technological development}

Competitive forces have been studied extensively in relation to technological development $[9,12,13]$. Already in 1993 Utterback and Suárez wrote that "greater degrees of competition will result in more rapid rates of technological change" [13, p. 1]. Below, we discuss three competitive forces and pressures to innovate that are found to be important for the continuation of technological development.

\subsubsection{Rivalry}

Rivalry takes place between established firms active in the same product market within a specific LEV field, for example between established car manufacturers. Rivals tend to compete especially through incremental innovation $[25,26]$. The positive effect of rivalry on technological development of LEVs has frequently been confirmed for rival car manufacturers. For example, Van Den Hoed [14] finds in his study on the commitment of car manufacturers to HFCV development that "[rivalry] forces play an important role for carmakers to invest considerably in these alternative [LEV] technologies ... although belief in these technologies may lack, companies still engage in these technologies in order not to lag behind" (p. 269). The same is found by Pohl and Yarime [9], who identified "intense competition, mainly between Toyota and Honda, as a crucial factor for the development in the [HEV and BEV] domain since the mid-1990s" (p.11). Others [15,24] stress that successful HEV development in turn triggered other firms to enter the field and contribute to further technological development. These and other studies (e.g. [23,27]) highlight that it is especially the interplay between rivalry and technological development that supported continued LEV development in the period 1990-2010. According to life cycle literature, rivalry becomes an especially strong force when the technology matures and enters an era of incremental innovation [5]. The relation between rivalry and continued technological development is captured in the following proposition:

Proposition 2. Increasing rivalry is positively related to continued waves of LEV development.

\subsubsection{Dispersion}

Large car manufacturers have been an important subject of studies on LEV development (e.g. $[3,7,9,14])$. This is justified by the fact that these firms make the largest contributions to LEV development $[3,7,9,14]$. However, there are also other firms that make important contributions. These firms include not only different tier suppliers [20], but also research institutes, providers of infrastructure and services and other organizations involved in LEVs. Dispersion refers to the extent to which different types of organizations contribute to technological development.

Increasing dispersion is expected to be positively related to continuation of waves of LEV development for several reasons. First, the more firms support a wave of LEV development, the less vulnerable this wave becomes to the disruptive effect of individual firms withdrawing their support for the wave of development. Second, when there are more firms active in the development of LEVs there is more competition, not only between car manufacturers as in the case of rivalry, but also between other firms that compete within and across (vertical integration) any segment of an LEV value chain. Stronger competition over the entire value chain triggers increased technological development by any firm in the value chain (instead of only by car manufacturers as in the case of rivalry). The relation between dispersion and continued technological development is captured by the following proposition:

Proposition 3. Increasing technological dispersion is positively related to continued waves of LEV development.

\subsubsection{Presence of new entrants}

Tushman and Anderson [5] stress that the contribution of new entrants to technological development is especially strong in the field of a competence-destroying technology; especially during an era of ferment. Competence-destroying technologies render obsolete the competences required to profit from existing technology, in the same way that the BEV and HFCV render obsolete some competences required to profit from the ICEV. Development of competence destroying technologies like the BEV and HFCV lower entry barriers and open up windows of opportunity for new entrants to enter the market $[5,13,18,28,29]$. New entrants include not only startups but also diversifying established firms moving into new markets [13]. Once new entrants have entered the market, they themselves engage in technological development through the exploitation of novel combinations of related technological fields, thereby boosting technological development [30]. Additionally, the presence of new entrants also triggers established firms to engage in development of the competence-destroying technology: the so-called 'incumbent challenger dynamics' [31]. Through these dynamics and the continuous influx of new entrants caused by 
technological development, technological development becomes continued:

Proposition 4. Stronger presence of new entrants is positively related to continued waves of competence-destroying LEV development.

Finally, the previously related competitive forces are also related to each other. Technological development triggers not only rival car manufacturers to enter a technological field and engage in development, but also firms in other product segments and especially new entrants. Through the previously described mechanisms of increased rivalry, dispersion and the presence of new entrants, technological development is expected to be continued. However, it is possible that technological development might trigger only one factor, and inhibit others. For example, when technological development triggers strong rivalry amongst car manufacturers, which consequently dominate the technological field and cause vertical integration, this might induce entry barriers for firms in other product segments and for new entrants coming from other sectors or startups. Consequently, dispersion and the presence of new entrants might be inhibited at the cost of increased rivalry. In such instances, the positive effects of one force might be undone by the negative effects of other forces. In such cases, it would be interesting to identify any dominance of one factor over the others. We make no predictions about the consequences of such instances for continued technological development, but only propose that when all forces increase, this will lead to continued LEV development.

\section{Methodology}

In this methodology section we first discuss the selection of patents as an indicator for technological LEV development. Second, we present the research design and data collection, including an elaboration on the search queries we constructed. Subsequently, we describe the operationalization of indicators used to study the propositions described in the previous section.

\subsection{Selection of the indicator of technological development}

Various indicators have been used to study LEV development, including media statements [22,32], prototypes [23,33], production models and sales figures [15,24], and patents [3,7]. However, not all of them are accurate as an indicator for actual technological development over time and to measure the competitive forces.

Prototypes, production models and car sales primarily reflect the technological development by car manufacturers and not of other firms, which we intended to include in our analysis through the measure of dispersion. Additionally, production models and sales figures do not give a thorough picture of early stage R\&D. Media statements and prototypes shown at auto shows serve as channels that enable car manufacturers to influence the perception of competitors, policy makers and the public regarding a certain type of LEV $[14,22]$. They can therefore be effective means to influence LEV specific competition, policy making and demand respectively, without reflecting actual technological development. Because of these potentially strategic purposes, media statements and prototypes are also less suitable indicators for actual technological development.

Patents, however, are used more for protecting internal intellectual property than for strategic positioning and influencing outsiders' perception. Consequently, they are a better indicator for $R \& D$ and actual technological development $[3,14,34]$ and are frequently applied in technological forecasting studies in related fields [35,36]. Furthermore, patents are applied for by various types of organizations and therefore enabled the analysis of rivalry, dispersion and the presence of new entrants. Finally, patents are easily available in large quantities in long time series, thereby allowing comprehensive longitudinal analyses [3,14,34]. However, patents also have some drawbacks: the tendency to patent differs over time and between countries, industries, firms and technologies [3,14,34]. We account for most of these differences by making relative instead of absolute comparisons. Unfortunately, like other patent studies, we could not account for firm level differences as a result of different Intellectual Property Rights strategies. Despite this setback, patents provide the most suitable indicator for this study.

\subsection{Research design and data collection}

As stated in the Introduction, in this study we first investigated the presumed positive relations between on the one hand rivalry, dispersion and the presence of new entrants and on the other hand broken and continued waves of LEV development. The early wave of BEV development and the wave of HFCV development represent broken waves, whereas HEV development represents a continued wave. ${ }^{3}$ Secondly, we applied these findings to the fourth and current waves of BEV development to assess if continued technological development is now more likely to occur than during previous broken waves.

Our research design postulates the exclusive study of waves of development, which from a methodological viewpoint is justified. It would be useless to study periods of decreasing interest because the dynamics by which organizations lose interest in a technology are irrespective of the relation between the competitive forces and technological development described in the Theoretical framework section.

In this longitudinal patent study we cover the timeframe 1990-2010, as LEV developments intensified in 1990 [20] and patent data after 2010 were unreliable due to the eighteen month secrecy period before patent publication [37]. To acquire patent data, we used the European Patent Office's Global Patent Index program [38] because it contains worldwide patent data, which ensured a complete capture of technological development worldwide. More importantly, the program allowed for an increased number of search terms, which was necessary to execute the search queries we developed.

The search queries we used to gather relevant patents can be divided into two categories: 'conventional queries' and 'component queries' (see Fig. 1). Conventional queries are the types of queries used in the existing literature that specify a particular type of LEV; as such, they specify a vehicular application by adding (vehicle OR automobile OR car) within a two word distance behind the words relating to the type of LEV. Component queries are queries that specify the

\footnotetext{
3 The Plug-in Hybrid Electric Vehicle (PHEV) has been left out of the analysis, as no sufficient patent data could be found on this type of vehicle.
} 
components of which a LEV is comprised. Fig. 1 shows that these components can be unique to a specific LEV, or applied in multiple LEVs. More information on the steps taken for search query construction can be found in Appendix I.

\subsection{Operationalization}

To study the different propositions, we make use of two populations of organizations depicted in Fig. 2. Group A in this figure represents the patents developed by a set of large car manufacturers that have played pivotal roles in LEV development $[3,7]$. This set comprises the fifteen largest car manufacturers according to the 2010 personal vehicle sales figures from the International Organization of Motor Vehicle Manufacturers [39]. They include Toyota, Volkswagen, General Motors, Hyundai, Honda, PSA, Nissan, Ford, Suzuki, Renault, Fiat, BMW, Daimler AG, Mazda and Mitsubishi. Group A was used for Propositions 1 and 2, i.e. to research waves of LEV development and rivalry. The analysis of this group makes use of both the conventional and the component level queries because the vehicular application, which was not specified in the component level queries, is guaranteed within this sample of car manufacturers.

Group B represents the patents developed by all other organizations that contributed to LEV development. In our analysis, this group is specifically studied to identify the new entrants specified in Proposition 4. To this group we only applied the conventional search queries because, unlike group A, this group does not necessarily work on vehicular product applications. Therefore, when we applied the component queries outside the scope of group A, we got so many irrelevant patents related to products other than cars, that we could not filter them all out. An 'electric motor' for example, is not only used in LEVs, but also in products ranging from torpedoes to elevators.

Finally, to study Proposition 3, related to dispersion of technological development, we compared the patents of groups $A$ and $B$ based on conventional search queries.

Below we discuss how we operationalized each proposition.

To operationalize the first proposition, we acquired data on the waves of technological development by using the average portfolio share of the sample of car manufacturers.

\section{Conventional queries:}

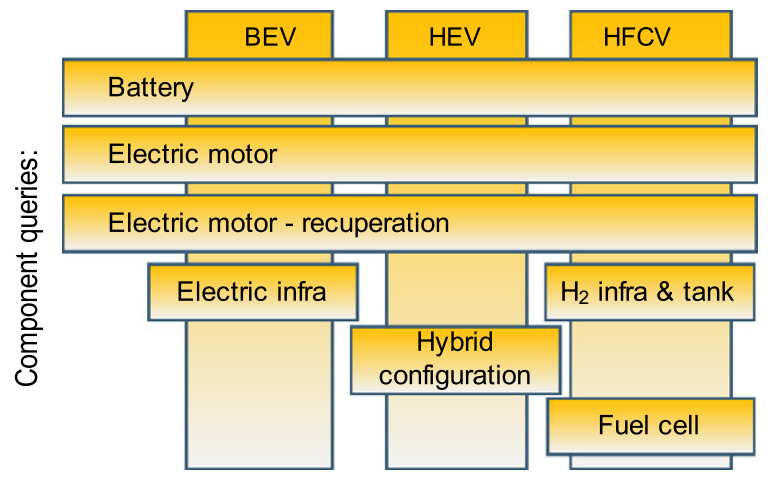

Fig. 1. Relation between the components (horizontal) and types of LEVs (vertical) included in this study.
This measure allowed us to control for biases in the absolute numbers of patents over time.

In order to study the second proposition, we measured rivalry by using the conditional entropy of organizational variety, which Frenken et al. [7] developed to measure rivalry in the field of LEV development. We applied this measure to the sample of rival car manufacturers. The conditional entropy shows the distribution of patent shares of each car manufacturer ' $j$ ' in the set of $n$ organizations within a certain type of LEV ' $i$ ' (see Eq. (1); for a comprehensive explanation see [7]). Entropy and thus rivalry pressure is high when the distribution of patent shares is distributed more equally amongst more rivals [7]. The formula reads as follows, for each moment of observation:

$H(Y \mid X i)=-\sum_{j=1}^{n}\left(\frac{P i j}{P i}\right) \ln \left(\frac{P i j}{P i}\right)$.

With regard to the third proposition, we argue that dispersion and its related competitive pressures are higher when more firms contribute more equally to technological development. We measured dispersion by the share in the total amount of patents that is not accounted for by the sample of car manufacturers. Looking at Fig. 2, dispersion was determined by the share of patents resulting from group $B /(A+B)$. Because car manufacturers have the highest number of patents in any LEV field, a high share of patents outside the set of car manufacturers indicates that patents are distributed over more firms, thus suggesting high dispersion.

For the fourth proposition we looked at the presence of new entrants, which can be startups or diversifying firms. Startups are firms that did not exist before our timeframe of study (1990). Diversifying firms are firms that started patenting an LEV during the timeframe of study, whereas their initial focus was or still is on a sector other than automotive. We measured the effect of new entrants on LEV development by identifying which of the thirty most important contributing organizations at least doubled their patents during the wave of development, compared to the same time period preceding the respective wave, and identified the new entrants amongst them. We looked at relative increases because the waves of development are also based on relative numbers, i.e. patent shares that increased every successive year. However, because HFCV and HEV development did not have enough patents for analysis in the period preceding the wave and because the period preceding the wave of BEV development in the early nineties fell outside the timeframe of analysis (1990-2010), we only focused on the current wave of BEV development.

\section{Results and analysis}

This results section is structured in line with the sequence of propositions. Accordingly, we start by identifying waves of development in Section 4.1. Subsequently, we discuss rivalry in 4.2; dispersion in 4.3 and the presence of new entrants in 4.4. Finally, in Section 4.5 we combine the data on these forces and describe how together they influence the continuation of waves of LEV development. 


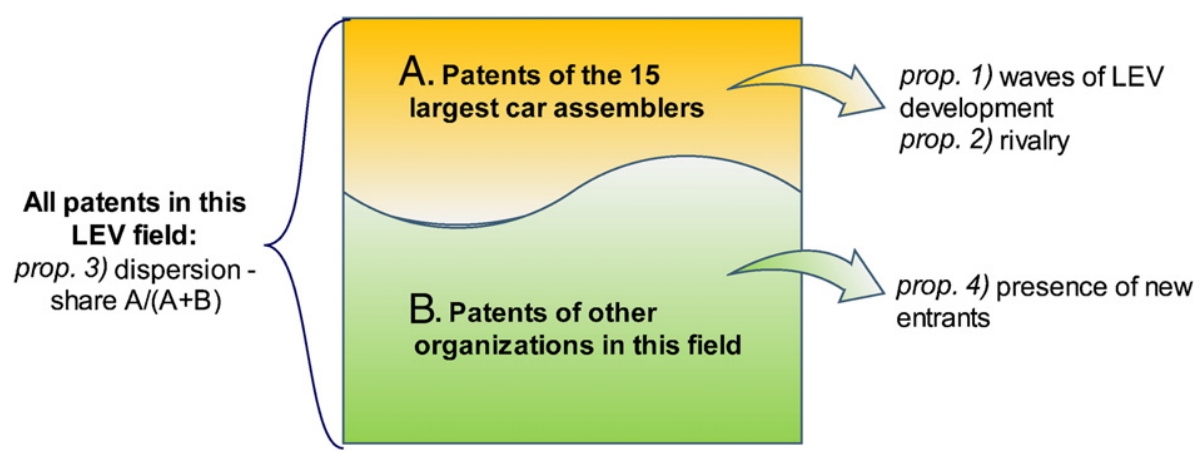

Fig. 2. How the different types of analyses relate to the set of car manufacturers and other organizations under research. (This figure does not represent real data.)

\subsection{Proposition 1: Verifying waves of LEV development}

In Fig. 3 the fifteen largest car manufacturers' annual portfolio shares per type of LEV for the period 1990-2010 are displayed. Fig. 3 presents the waves of LEV development as solid lines, whereas the periods without high expectations are indicated by dotted lines. The first broken wave of development is that of BEV development during the period 1990-1994. Subsequently, there is a wave of continued HEV development from 1996 onwards with a second boost in development from 2006 until 2008, well after commercial success [15], followed by stagnation. At the same time, a broken wave of HFCV development takes place from 1998 to 2007. Finally, the figure verifies that the current wave of BEV development is supported by increased patent activities and therefore constitutes not only an increase in the number of prototypes and production models as found by [19], but also in R\&D. This wave of BEV development took off around 2006. ${ }^{4}$ The data in Fig. 3 coincide well with the waves of development identified in previous studies. ${ }^{5}$ These corresponding findings support "Proposition 1 : Waves of LEV development identified in previous studies are characterized by technological progress and therefore reflected by peaks in patent data".

\subsection{Proposition 2: Rivalry within waves of LEV development}

Fig. 4 displays the trends in organizational variety during the waves of LEV development identified in the previous section between the fifteen largest car manufacturers in the fields of BEV, HEV and HFCV, by the use of a conditional entropy measure. ${ }^{6}$ This figure shows that during the continued wave of HEV development, rivalry increases over time and that during

\footnotetext{
4 The fact that the share of BEV patents is smaller than the share of HFCV patents in 2010 does not mean that HFCV was getting more attention; this difference can also be explained by the differences in tendencies to patent over technology fields [14].

${ }^{5}$ However, the wave of BEV development that Frenken et al. [7] identify in the early nineties seems to have a time lag compared to ours, as the wave they identify starts in 1994, while we observe an increase in BEV development already in 1990 . Their time lag might be explained by their use of a patent's 'issue date' compared with our 'date of application', as the latter minimizes the time elapsed after invention.

${ }^{6} 1998$ is missing in the HFCV trend because too few data was available to appropriately calculate the dispersion measure for that year.
}

the broken wave of HFCV development, rivalry decreases over time. This suggests a positive correlation between rivalry and continuation of technological development. However, the broken wave of BEV development in the early nineties also displays an increasing trend in rivalry; in this case there is a negative correlation. This negative correlation contradicts the expected positive correlation, but as the Theoretical framework section suggested, it can be explained by a coinciding decrease in dispersion, which will be described in the next section. ${ }^{7}$ Nevertheless, it is impossible to confirm "Proposition 2: Increasing rivalry correlates with continued waves of LEV development" on the basis of these data. Section 4.5 further analyzes how the coincidence of rivalry and dispersion affects continuation of LEV development.

\subsection{Proposition 3: Dispersion within waves of LEV development}

Fig. 5 displays the trends in dispersion, measured by the share of patents that fall outside the scope of the set of large car manufacturers, during waves of LEV development. The higher the share that falls outside this set, the more dispersed technological development is. On the one hand, Fig. 5 shows trends of decreasing dispersion for the broken waves of BEV (in the early 1990s) and HFCV development. On the other hand, HEV development shows an initial decline in dispersion, which is explained by our data showing that Toyota and Honda dominate HEV development, especially in the period 1996-2004. Subsequently, dispersion increases in the period 2004-2010 as other firms enter the field. This suggests that not only rival car manufacturers were triggered to enter the field of HEV by its commercial success [15,24], but also organizations outside the set of car manufacturers. Overall, the continuation of the wave of HEV development coincides with increasing dispersion. These findings support "Proposition 3: Increasing technological dispersion is positively related to continued waves of LEV development". On a different note, it is surprising to see that over the 21 year period, the average dispersion in the field of BEV (81.0\%) is structurally significantly higher than that of HEV (39.2\%) and HFCV (19.8\%).

\footnotetext{
7 Further to the negative effect of decreasing dispersion, several studies $[16,21,43]$ stress that the relaxation of the Zero Emission Vehicle regulation, mandated by the Californian Air Resources Board, contributed to the discontinuation of this wave of BEV development.
} 


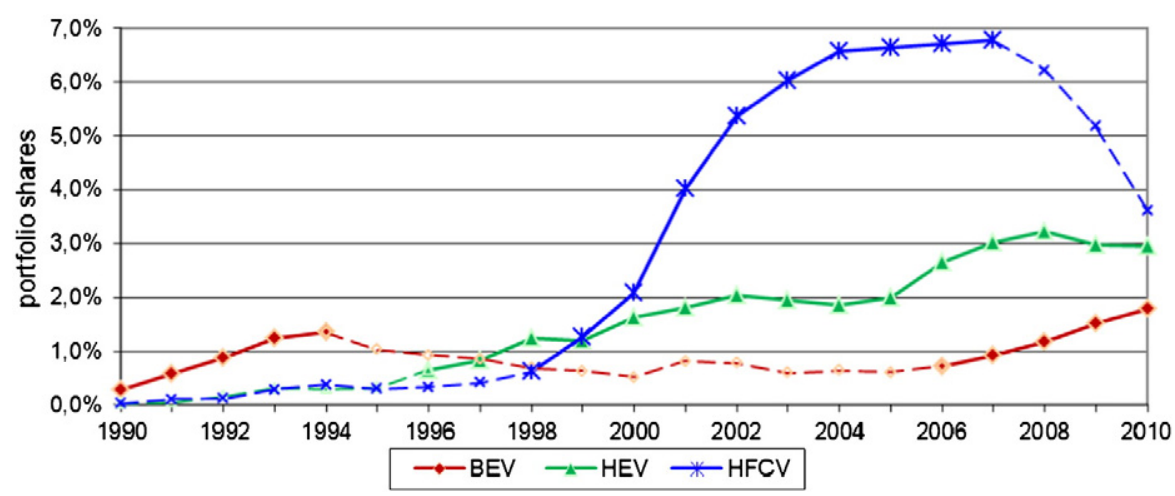

Fig. 3. Trends in the fifteen car manufacturers' annual portfolio share per type of LEV over the period 1990-2010.

Furthermore, the current wave of BEV development is characterized by an increase in dispersion, which means that although the patent portfolio share of the fifteen largest car manufacturers increases strongly (as signified by the wave of development), the share of these firms in the total number of BEV patents declines. This suggests that although car manufacturers are increasingly developing BEV technology, they cannot keep up with the general rate of development in the field of $\mathrm{BEV}$. This may imply that their competitive position in BEV development relative to other organizations in this field is declining, or that they are focusing their activities. The fact that increasing numbers of firms are contributing to the wave of BEV development suggests that continuation of this wave is likely.

\subsection{Proposition 4: The role of new entrants}

Table 1 presents the firms in the top thirty most important patent owners over the wave of BEV development (2007-2010) that at least doubled their number of patents compared to the four-year period preceding this wave (2003-2006). Table 1 shows that only two incumbent firms account for a large part of the current wave of BEV development, compared with 5 startup firms and 4 diversifying firms. These new startup firms are active in different loci of the BEV-supply chain, e.g. Tesla Motors and Leo Motors (car manufacturer/developer), V-ENS
(BEV-manufacturing consultant), Better Place (infrastructure provider) and V2Green (vehicle-grid integration). In conclusion, new entrants, both startups and diversifying organizations, are playing an important role in the current wave of development that involves the competence-destroying BEV technology. Although we could not study "Proposition 4: The presence of new entrants is positively related to continued waves of competence destroying LEV development" over the different fields of $\mathrm{LEV}$, this proposition suggests that the presence of various new entrants sustains the current wave of BEV development.

\subsection{Overview of the results}

In our Theoretical framework section we suggested that it is not necessarily the individual competitive forces that trigger continued waves of LEV development but the combination of these forces. In this section we focus on how rivalry and dispersion (as the presence of new entrants could not be measured for all waves of LEV development) together affect the continuation of waves of LEV development. Table 2 provides an overview of the way these concepts coincide with the identified waves of LEV development. Table 2 shows that, when rivalry and dispersion decrease, i.e. in the case of HFCV, this coincides with a broken wave of development. Moreover, when rivalry and dispersion increase, i.e. in the case of HEV, this coincides

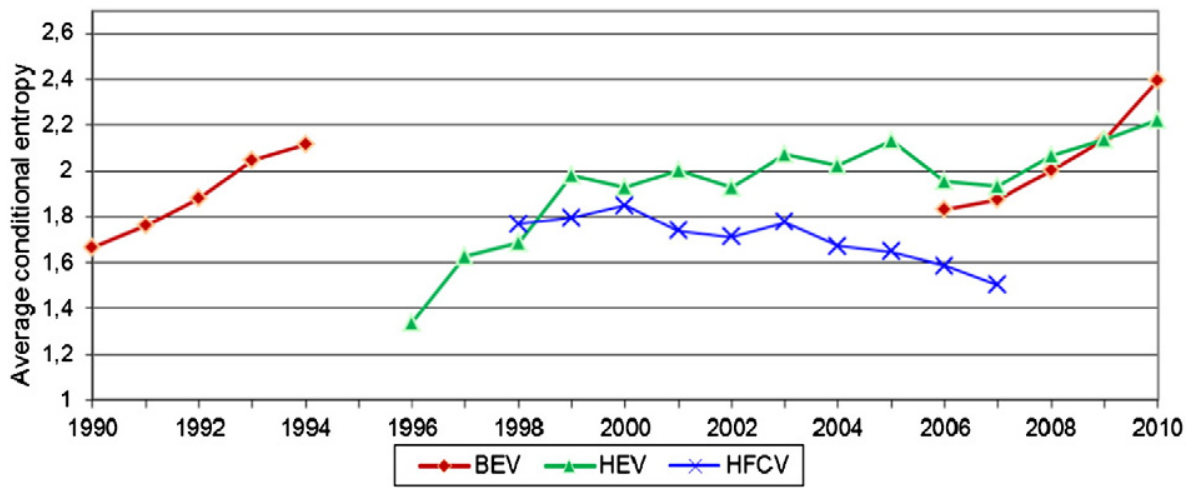

Fig. 4. Rivalry, measured by conditional entropy of organizational variety within the fields of BEV, HEV and HFCV over the period $1990-2010$. 


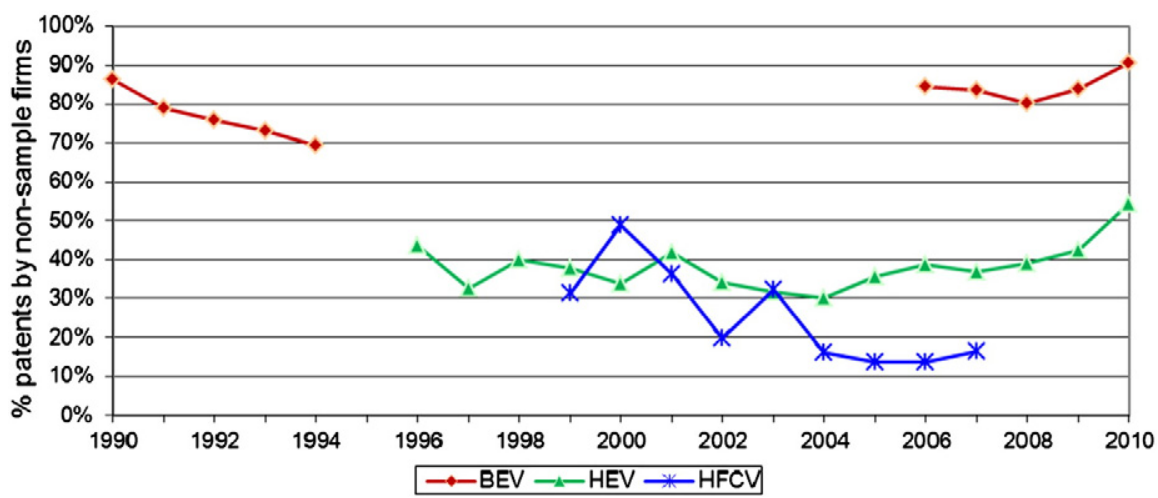

Fig. 5. Patent share of organizations outside the set of fifteen largest car manufacturers in the total number of patents for different types of LEVs during waves of LEV development over the period 1990-2010.

with a continued wave of development. These findings seem to suggest that both rivalry and dispersion should increase for a wave of LEV development to become continued. However, the broken wave of BEV development shows that when rivalry increases and dispersion decreases, this does not relate to a continued wave of development. This suggests that the negative effect of dispersion might be more significant than the positive effect of rivalry in relation to continued development.

Looking at the current wave of BEV development, we find that not only rivalry and dispersion support continued development, but, as suggested by Proposition 4, also the presence of new entrants. This suggests that the current wave of BEV development is likely to become continued due to the different competitive pressures created by the numerous and different types of actors that are supporting this wave of technological development.

\section{Conclusions and discussion}

This research tackled the question "How did the forces of rivalry, dispersion and the presence of new entrants affect the duration of earlier waves of LEV development and how do these competitive forces affect the chances of continuation of the current wave of BEV development?" With respect to the first part of this question, our empirical study appears only to confirm the individual positive relationship between dispersion and the continuation of earlier waves of LEV development. Moreover, our case studies suggest that the combination of rivalry and dispersion is positively related to the continuation of waves of LEV development. The data did not allow us to test this relationship for the presence of new entrants, which theory proposed to positively influence continued LEV development. Because our findings are drawn from only three case studies and the effect of the presence of new entrants could not be established, it is necessary to improve the validity of the effect the three competitive forces have on continued technological development. Therefore, we recommend future research to further look into this relation. With respect to the second part of our question, we find that rivalry and dispersion each supports future continuation of the current wave of BEV development, and that new entrants play an important role in current BEV development. In other words, current BEV developments are driven by an increasing number of organizations, including new entrants. Through competitive pressures these organizations continuously induce each other to invest more in the technological development of the BEV. We expect these dynamics to sustain the current wave of $\mathrm{BEV}$ development.

This study has taken a different approach to assess the chances of success of a new technology by focusing on how competitive forces affect the supply side of LEVs. In taking this specific focus, our study did not take into account some aspects that influence the success of LEVs. For example, the role of institutional developments and emergence of markets were, although important, not incorporated in this study. Another important aspect that should be taken into account is the interaction of the established ICEV that still dominates the automotive industry, with LEVs [15]. Sailing-ship effects have been identified for the ICEV [3], which can hamper LEVs' chances of success. Because this study has a specific focus on competitive forces and the supply side, it is complementary to, and accordingly should be consulted within the context of LEV assessments that have a different focus.

To recap the contributions of this paper stated in the Introduction, we firstly provide a more contemporary study on

Table 1

Firms accounting for the largest increase in BEV patents between the periods 2003-2006 and 2007-2010.

\begin{tabular}{lllll}
\hline Organization & $\begin{array}{l}\text { Patents } \\
\text { 2003-2006 }\end{array}$ & $\begin{array}{l}\text { Patents } \\
\text { 2007-2010 }\end{array}$ & $\begin{array}{l}\text { Contributing } \\
\text { rank in 2010 }\end{array}$ & $\begin{array}{l}\text { Type of } \\
\text { organization }\end{array}$ \\
\hline $\begin{array}{l}\text { Korea Adv. Inst. } \\
\text { of Science }\end{array}$ & 0 & 182 & 1 & Diversifying \\
$\begin{array}{l}\text { Chery } \\
\quad \text { Automobile }\end{array}$ & 5 & 114 & 5 & Incumbent \\
$\begin{array}{l}\text { Tesla Motors } \\
\text { Siemens }\end{array}$ & 0 & 90 & 7 & Startup \\
RWE & 10 & 80 & 9 & Diversifying \\
General Electric & 0 & 47 & 13 & Diversifying \\
Better Place & 0 & 46 & 14 & Diversifying \\
V2Green & 0 & 41 & 15 & Startup \\
V ENS & 0 & 35 & 18 & Startup \\
Bosch & 6 & 33 & 20 & Startup \\
Leo Motors & 0 & 36 & 17 & Incumbent \\
\hline & 28 & 22 & Startup \\
\hline
\end{tabular}


Table 2

Overview of the results.

\begin{tabular}{|c|c|c|c|c|}
\hline \multirow[b]{2}{*}{ Indicator } & \multicolumn{4}{|c|}{ Wave of LEV development } \\
\hline & BEV '90s & HFCV & HEV & BEV currently \\
\hline Rivalry & $(+)$ increase & $(-)$ decrease & $(+)$ increase & $(+)$ increase \\
\hline Dispersion & $(-)$ decrease & $(-)$ decrease & $(+)$ increase & $(+)$ increase \\
\hline Presence of new entrants & (..) n.a. & (..) n.a. & (..) n.a. & $(+)$ yes \\
\hline Sustained wave? & $(-)$ no & $(-)$ no & $(+)$ yes & (?) uncertain \\
\hline
\end{tabular}

the forecasting of continued development of the BEV that is based on improved search queries as well as an improved set of competition-based indicators that incorporate all relevant actors. Secondly, our analysis has shed new light on the dynamics of technological development during the life cycle's era of ferment. Thirdly and maybe most importantly, our newly introduced set of competition-based factors is useful for technological forecasting in general. Little attention has been paid so far to the role of technological competition in technological forecasting. Although the competitive force rivalry has been studied in a similar context by Frenken et al. [7], we widened the scope on competitive forces by also including dispersion and the presence of new entrants. Our analysis shows that adding dispersion is important to understand why some waves of technological development ended. We recommend further research to validate the effect of these competitive forces on the continuation of technological development; especially how this effect changes when the technology under focus matures, as our study was delineated to emerging technologies in eras of ferment.

Based on our study, we make some recommendations for further research. First, we found major structural differences between the dispersion of BEVs on the one hand, and HEVs and HFCVs on the other. We recommend further research to look into why large car manufacturers so extensively dominate HFCV development, whereas their role in BEV development is relatively small.

Additionally, we identified a relation between high dispersion of BEV development and the high number of startups in this field. This relation suggests that dispersion has an entry barrier lowering effect. The fact that the BEV relies on more mature technological fields and the fact that BEV development is dispersed amongst a larger number of organizations, suggest that BEV knowledge is more competitively available. Illustrative is the provision of batteries by a wide range of suppliers that are diversifying their market range [40]. More competitively available knowledge lowers entry barriers, especially for startups that incorporate different knowledge/components to create a product or service, e.g. car manufacturers. This explains the presence of startups, especially startups like Tesla and Leo Motors, in the field of BEV. Through these same dynamics, the lack of dispersion and the absence of related mature technological fields might also explain why there are no startup car manufacturers involved in the development of the competence-destroying technology of HFCV [32]. A complementary explanation for the lack of new entrants in this field is the lack of infrastructure and demand for the expensive HFCVs. Because of the uncertainty on this topic, we recommend future research to further analyze the relation between dispersion and the entrance of startups.
Finally, in this study we only focused on the development of LEV knowledge, but the diffusion of LEV knowledge through networks of inter-firm alliances is also found to play an important role in the transition towards LEVs [41]. Because firms use both internally developed knowledge and externally acquired knowledge to create products as complex as LEVs [41], we recommend future research to investigate the roles of both internal development and external acquisition of LEV knowledge. This will provide a more comprehensive view on the possible transition towards LEVs.

\section{Acknowledgments}

We want to thank the Netherlands Organization for Scientific Research (NWO) for funding this research.

\section{Appendix I. Steps used to construct search queries}

It is complicated to construct good search queries. For example, there are studies using search queries like 'battery AND electric AND vehicle' for BEVs. Such queries yield patents that can relate to any type of vehicle that uses batteries, which generate electric current. Hence, there will be a lot of irrelevant patents, or 'noise' that reduces the validity of studies employing ill constructed search queries. To construct more valid search queries we apply some rules of thumb extracted from previous studies $[3,7,14]$ as well as ones derived by ourselves.

1. First, our search queries focus on words in the 'title and abstract' field instead on patent classes. We did not apply patent classes for two reasons. First, patent classes do not always specify the vehicular application of the class, causing them to yield irrelevant patents. For example, Pilkington and Dyerson [16], using a patent class search on BEVs, found that only $36 \%$ of their patents specified the correct (road) vehicular application. Second, LEVs incorporate many 'sub-technologies' that all need to be captured. In addition, "emerging technologies not clearly provided for in any one class may develop in more than one class simultaneously" [42]. Hence, the different LEV sub-technologies are captured by different patent classes, making it complicated to identify all of the numerous relevant patent classes within the continuously growing pool of over 70,000 existing patent classes. Finally, we prefer searching in the patent text itself over a derivative of it (patent classes), which is not constructed for our type of analyses but for the purpose of archiving patents. The use of key words allows us to specify vehicular applications and search for both the type of LEV and its different components.

2. Second, when searching for a specific LEV type or component, we use search terms to exclude patents belonging to 
other LEVs and related components, as is done by previous patent studies [7,14]. However, these studies excluded only HEVs and HFCVs, whereas we also systematically exclude BEVs and ICEVs and their related components.

3. Third, with respect to the patent applicant field, we control for Asian inventors and Japanese Keiretsu-firms that commonly carry the same name as an automotive manufacturer, by specifically searching for the automotive manufacturer by using for example 'Mitsubishi' - two words separated from - 'Motor'.

4. Fourth, in order to make sure that the patents we find are relevant and not counted double in the database, for example because the initial attempt to gain a patent grant failed, we use a 'publication level filter'. We do not make use of a 'patent family filter', because as Oltra and Saint Jean [3] stress, the fact that the same invention might be patented in different countries is an indication of its strategic importance, and hence its importance to technological development, which justifies its overweighting in our analysis.

5. Fifth, after applying the 'publication level filter' we use the Global Patent Index program's function to order the acquired data on the basis of the 'date of filing', which refers to the date the applicant filed for the patent. Using the date of filing in this successive step adds to the precision of the analysis as it reduces the time-lag with the moment of invention, i.e. the moment at which technological development actually took place.

The following combination of terms represents part of the conventional search query that was used to identify BEV patents. Time and applicant were left out.

$\mathrm{WORD}=\left(\right.$ electric $^{*}+2 \mathrm{~W}$ (vehicle OR car OR automobile $)$ OR battery $+2 \mathrm{~W}$ (vehicle OR car OR automobile)) ANDNOT (hybrid OR "fuel cell" OR "fuel cells" OR "internal combustion engine" OR hydrogen OR H2 OR "electric car window" OR "electric car wire" or ((train or trains) ANDNOT (powertrain or powertrains)) or locomotive or "power line").

\section{References}

[1] E. Uherek, T. Halenka, J. Borken-Kleefeld, Y. Balkanski, T. Berntsen, C. Borrego, et al., Transport impacts on atmosphere and climate: land transport, Atmos. Environ. 44 (37) (2010) 4772-4816.

[2] A. Tukker, Leapfrogging into the future: developing for sustainability, Int. J. Innov. Sustain. Dev. 1 (2) (2005) 65-84.

[3] V. Oltra, M. Saint Jean, Sectoral systems of environmental innovation: an application to the French automotive industry, Technol. Forecast. Soc. Chang. 76 (4) (2009) 567-583.

[4] IEA, Clean energy progress report, IEA Input to the Clean Energy Ministerial, 2011.

[5] M.L. Tushman, P. Anderson, Technological discontinuities and organizational environments, Adm. Sci. Q. 31 (3) (1986) 439-465.

[6] K.G. Hoyer, The battle of batteries: a history of innovation in alternative energy cars, Int. J. Altern. Propuls. 1 (4) (2007) 369-384.

[7] K. Frenken, M. Hekkert, P. Godfroij, R\&D portfolios in environmentally friendly automotive propulsion: variety, competition and policy implications, Technol. Forecast. Soc. Chang. 71 (5) (2004) 485-507.

[8] H. Van Lente, Promising Technology: the Dynamics of Expectations in Technological Developments, Faculteit Wijsbegeerte en Maatschappijwetenschappen, Universiteit Twente, Enschede, 1993.

[9] H. Pohl, M. Yarime, Integrating innovation system and management concepts: the development of electric and hybrid electric vehicles in Japan, Technol. Forecast. Soc. Chang. 79 (8) (2012) 1431-1446.

[10] S. Bakker, H. van Lente, R. Engels, Competition in a technological niche: the cars of the future, Tech. Anal. Strateg. Manag. 24 (5) (2012) 421-434.
[11] G. Mom, The Electric Vehicle: Technology and Expectations in the Automobile Age, John Hopkins University Press, Baltimore, MD, 2004.

[12] K. Klein, Dynamic Economics, Harvard University Press, Cambridge, MA, 1977.

[13] J.M. Utterback, F.F. Suárez, Innovation, competition, and industry structure, Res. Policy 22 (1) (1993) 1-21.

[14] R. Van Den Hoed, Commitment to fuel cell technology?: How to interpret carmakers' efforts in this radical technology, J. Power Sources 141 (2) (2005) 265-271.

[15] M. Dijk, M. Yarime, The emergence of hybrid-electric cars: innovation path creation through co-evolution of supply and demand, Technol. Forecast. Soc. Chang. 77 (8) (2010) 1371-1390.

[16] A. Pilkington, R. Dyerson, Innovation in disruptive regulatory environments: a patent study of electric vehicle technology development, Eur. J. Innov. Manag. 9 (1) (2006) 79-91.

[17] S. Klepper, Entry, exit, growth and innovation over the product life cycle, Am. Econ. Rev. 86 (3) (1996) 562-583.

[18] W.J. Abernathy, J.M. Utterback, Patterns of industrial innovation, Technol. Rev. 80 (7) (1978) 40-47.

[19] W. Sierzchula, S. Bakker, K. Maat, B. van Wee, The competitive environment of electric vehicles: an analysis of prototype and production models, Environ. Innov. Societal Transit. 2 (2012) 49-65.

[20] R. Kemp, Zero emission vehicle mandate in California: misguided policy or example of enlightened leadership? in: C. Sartorius, S. Zundel (Eds.), Time Strategies, Innovation and Environmental Policy, Edward Elgar, Cheltenham, 2005, pp. 169-191.

[21] G. Collantes, D. Sperling, The origin of California's zero emission vehicle mandate, Transp. Res. A Policy Pract. 42 (10) (2008) 1302-1313.

[22] S. Bakker, The car industry and the blow-out of the hydrogen hype, Energy Policy 38 (11) (2010) 6540-6544.

[23] T. Magnusson, C. Berggren, Entering an era of ferment - radical vs incrementalist strategies in automotive power train development, Tech. Anal. Strateg. Manag. 23 (3) (2011) 313-330.

[24] J.J. Chanaron, J. Teske, Hybrid vehicles: a temporary step, Int. J. Automot. Technol. Manag. 7 (4) (2007) 268-288.

[25] R.R. Nelson, S.G. Winter, An Evolutionary Theory of Economic Change, Cambridge, Belknap, 1982.

[26] C.M. Christensen, The Innovator's Dilemma: When New Technologies Cause Great Firms to Fail, Harvard Business School Press, Boston, MA, 1997.

[27] B. van Bree, G.P.J. Verbong, G.J. Kramer, A multi-level perspective on the introduction of hydrogen and battery-electric vehicles, Technol. Forecast. Soc. Chang. 77 (4) (2010) 529-540.

[28] J. Blees, R. Kemp, J. Maas, M. Mosselman, Barriers to Entry. Differences in Barriers to Entry for SMEs and Large Enterprises, H200301, 2003.

[29] B. Jovanovic, G. MacDonald, The life-cycle of a competitive industry, J. Polit. Econ. 102 (2) (1994) 322-347.

[30] J.A. Schumpeter, R. Opie, A.H. Hansen, The theory of economic development, J. Polit. Econ. 44 (4) (1936) 560-563.

[31] S.M. Ansari, P. Krop, Incumbent performance in the face of a radical innovation: towards a framework for incumbent challenger dynamics, Res. Policy 41 (8) (2012) 1357-1374.

[32] R. Van den Hoed, Driving Fuel Cell Vehicles: How Established Industries React to Radical Technologies, Drukkerij Tan Heck, Delft, 2004.

[33] S. Bakker, H. Van Lente, M.T.H. Meeus, Dominance in the prototyping phase - the case of hydrogen passenger cars, Res. Policy 41 (5) (2012) 871-883.

[34] D. Archibugi, M. Pianta, Measuring technological change through patents and innovation surveys, Technovation 16 (9) (1996) 451-468.

[35] T.U. Daim, G. Rueda, H. Martin, P. Gerdsri, Forecasting emerging technologies: use of bibliometrics and patent analysis, Technol. Forecast. Soc. Chang. 73 (8) (2006) 981-1012.

[36] G. Harell, T.U. Daim, Forecasting energy storage technologies, Foresight 11 (6) (2009) 74-85.

[37] USPTO, USPTO will begin publishing patent applications, http://www. uspto.gov/news/pr/2000/00-72.jsp ed., 2000, 2012.

[38] EPO, patent information services for experts, https://data.epo.org/expertservices/start.html ed., 2012, 2012.

[39] OICA, world motor vehicle production, http://oica.net/wp-content/ uploads/ranking-2010.pdf ed., 2011, 2012.

[40] M. Lowe, S. Tokuoka, T. Trigg, G. Gereffi, Lithium-ion Batteries for Electric Vehicles: the U.S. Value Chain, 2010.

[41] W. Sierzchula, S. Bakker, K. Maat, Alliance Formation in the Electric Vehicle Industry during an Era of Ferment, C7, 2012, pp. 216-233.

[42] USPTO, overview of the U.S. Patent Classification system (USPC), http:// www.uspto.gov/patents/resources/classification/overview.pdf ed., 2012, 2012.

[43] R. Hoogma, Exploiting technological niches, Strategies for Experimental Introduction of Electric Vehicles, Twente University Press, Enschede, 2000 . 
Joeri Wesseling is a PhD student at Utrecht University, The Netherlands. In his research he combines system- and firm-level perspectives to study the role of incumbent car manufacturers in the transition towards Low Emission Vehicles. He graduated as a Master of Science at Utrecht University in Science and Innovation Management.

Dr. Jan Faber is associate professor of Innovation Studies in the department of Innovation, Environmental and Energy Sciences at Utrecht University. His research and teaching activities are focused on technology related venturing. He supervises MSc-SIM and PhD students on topics related to technology based product and process innovations by established and new firms. Jan Faber has a background in Economic Geography (MSc., 1980) and Political Geography (PhD., 1987).
Prof. Dr. Marko Hekkert is professor of Dynamics of Innovation Systems at the section Innovation Studies, research director of the department of Innovation and Environmental Sciences at Utrecht University, and scientific director of the Copernicus Institute. He coordinates research and education in the field of sustainable technology development and dynamics of technological innovation systems. He supervises several Ph.D. students and post-docs on topics related to the transition to a sustainable energy system, uncertainties in energy transitions, and energy innovation systems. Marko Hekkert has a background in Chemistry (MSc. 1995) and PhD (2000) in energy and material systems modeling. 